\title{
Translational Research in Cancer Drug Development
}

\author{
Edy Meiyanto*, Adam Hermawan, Anindyajati \\ Cancer Chemoprevention Research Center \\ Faculty of Pharmacy, Universitas Gadjah Mada, Yogyakarta \\ $\mathrm{http} / / \mathrm{ccrc}$.farmasi.ugm.ac.id
}

\begin{abstract}
The development of cancer treatment were initiated by the existence of human's effort to treat by applying certain materials which is mostly part(s) or extracts of plants, which are now adapted as traditional herbal medicine. The discovery of new drugs was based on intuition and empirical evidence. Thus, high luck factor was involved in a successful treatment with unguaranteed reproducibility. One example of drug being developed through conventional drug development is Taxol. Taxol is an extremely complex natural product and requires a bunch of hard work with high level of serendipity to be discovered as antitumor agent. Recently, rapid development in human biology and technology allow a change in drug discovery strategy by minimizing the luck factor. Targeted therapy has been a very promising strategy of drug development research, especially in cancer treatment. Although cancer has been known as a disease with very complex cellular and histo-pathophysiology, the abundance of studies on proteins, such as receptors and hormones, as the hallmarks of cancer allows us to explore carcinogenesis suppression further based on molecular targeted therapy. Kinases, one type of protein involved in signal transduction regulating cell growth and differentiation, could be the proteins that are proposed to be inhibited in suppressing tumor growth. An interesting example of the drug being discovered based on molecular modeling is the discovery of lapatinib as anticancer with specific target on HER-2 and EGFR to overcome the resistance of cancer to Herceptin caused by elevated level of EGFR expression.
\end{abstract}

Keywords: targeted therapy, cancer, translational drug development

\section{INTRODUCTION}

Cancer is a disease with a molecular cause of which vary according to each type. An alternative therapeutic target is the inhibition of proteins involved in signaling processes leading to the growth and development of cancer cells and the proteins involved in the resistance mechanisms of cancer. Systemic chemotherapy on cancer shows less effectiveness and selectiveness. It has toxic effects on normal cells, too.

Breast cancer, a sample of major death cause, is the most common cause of cancer death in several decades. The molecular mechanism of breast cancer is not fully understood, but it is possibly related to the expression of oncogenes such as c-myc, ERBB2, and Ras (Bouker et al., 2005). Breast cancer is also caused by mutations of BRCA1 (breast cancer, type 1), BRCA2 (breast cancer, type 2), and p53 gene (Kumar et al., 2000). The other possible mechanism is the inactivation of p53 wild-type resulting in the loss of function as a tumor suppressor gene (Hanahan and Weinberg et al., 2011). The failure of breast cancer therapies are mostly caused by resistance or multidrug resistance. This phenomenon is mediated by breast cancer resistance protein (BCRP), such as $\mathrm{P}$ glycoprotein (Pgp) (Imai et al., 2004). Thus, developing a specific drug for resistant breast cancer therapy to reduce death of breast cancer patients is such an urgent issue.

Conventional drug discovery began with virtually the same methods belong to the early antibiotics. Bioassays were used to screen large libraries of natural products, phytochemicals, or synthetic organic compounds to find a few bioactive chemicals.

*Corresponding author e-mail : meiyan_e@ugm.ac.id 
We could barely find compounds derived from screening to be directly useful as anticancer drugs. The candidate must be elaborated to a drug through repetitive synthesis of chemical analogs to improve its specificity, potency, bioavailability, and safety. Many years needed to elaborate a screening drug candidate into a preclinical drug development candidate.

Nevertheless, most candidates failed to be synthesized in an acceptable amount and accurately predict key aspects of drug behavior in human clinical trials. As a result of the high failure, the cost of drug development is getting higher and reach $\$ 10$ million budget per drug item (Matsumoto, 2008).

The cancer therapy has been switched to molecular targeted therapy that is based on protein library and chemical library (synthetic and phytochemicals) (Lee et al., 2011). Molecular targeted therapy ensures more effectiveness and efficiency since only tumor cells, not the normal cells would be affected. Specific drug for molecular targeted therapy discovery is important to be the focus of cancer drug development. And the resistance being involved in molecular targeted therapy would be also a focus in order to overcome resistance problem.

\section{Conventional Drug Development}

Indonesia, as one of "megabiodiversity" countries of the world, possesses a huge number of bio-resources which can be applied to a wide range of natural products, such as herbal/traditional medicine for cancer therapy as both as first-line drug of therapy and as complementary drug of conventional chemotherapeutic agents in combinational therapies. Drug development in Indonesia started with the applications of traditional medicine. Currently, both natural products chemists and phytochemists believes that the secondary metabolites contained in natural products are mostly used in the purpose of mostly self defense against harmful effects of toxins, carcinogens, or mutagens found in the plant (Mitscher et al., 1986) or attack by external predators (Woodbury et al., 1961). Pharmacological tests was done to proof their activity, starting from collection of samples, extraction, bioassay, pre-clinical study, formulation, until finally clinical trials are conducted.

One example of drug being developed through conventional drug development is Taxol. Having the mechanism of antitumor activity through binding to a protein, tubulin, causing the inhibition of cell division, taxol has been called as the best new anticancer agent being developed from natural products, showing efficacy against ovarian cancer (Wall and Wani, 1996), even being referred as 'the most important new drug we have had in cancer in 15 years by NCI (Kolata, 1991). Taxol is an extremely complex natural product, possessing the molecular weight of 853 , forming the compound $\mathrm{C}_{47} \mathrm{H}_{51} \mathrm{NO}_{14}$ (Fig. 1) (Wani et al., 1971). Just like many previous investigations of biocompounds' activity, the discovery of this antitumor agent requires a bunch of hard work with high level of serendipity (Wall and Wani, 1996). In the early 1960s, as part of the NCI-United States Department of Agriculture (hereafter USDA) plant screening program, taxol was found to be present in the bark of the Pacific yew (Taxus brevifolia), a slow growing tree mainly in the Pacific Northwest of the United States, in Oregon and Washington. Their development into clinically active agents lasted for about 30 years, from the early 1960s to the 1990s (Fig.2) (Cragg and Newman, 2005).

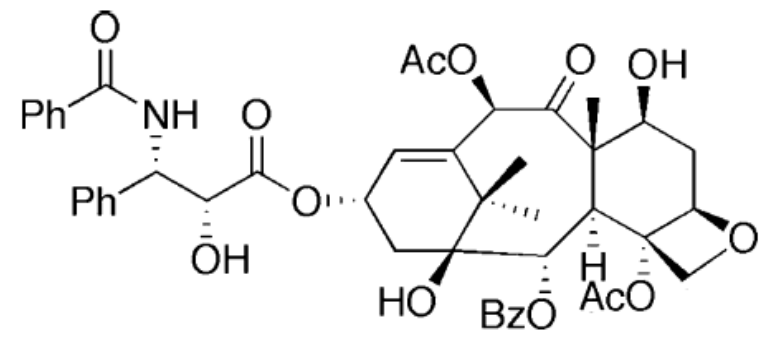

Figure I. Structure of Taxol 
1962: Bark was first collected

1964: Extract observed to be cytotoxic on several types of cancer cells 1977: Study on mechanism of action began

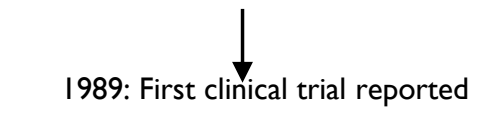
1994: Approved for second-line treatment of metastatic breast cancer by FDA

Figure 2. Development of Taxol as chemotherapeutic agent

The bark was first collected in 1962, then the extract was found to be strongly cytotoxic against several types of cancer cells two years later (Walsh and Goodman, 1999). The study of the mechanism of action of this molecule was initiated in 1977 (Horwitz, 2004), and taxol bioactivity was then demonstrated at first in 1979, and the first results of clinical trials were reported a decade later, followed by the announcement of taxol's potential in the treatment of ovarian cancer to the public (Suffness, 1994). FDA approved taxol as an effective chemotherapeutic agent against a wide range of tumor in 1992 (Kohler and Goldspiel, 1994). In 1998, taxol was approved for use against ovarian and advanced breast cancer in many parts of the world, even has been the first-line drug of choice in ovarian cancer treatment; and is potential to be used against other types of cancer. Nowadays, taxol is widely used in about one fourth of cancer treatment incidence.

Following the announcement of taxol's potential as anticancer agent, controversies came along. The issue of developing cancer chemotherapy versus the issue of environmental protection came up, since stripping the bark from the yew killed the tree (Walsh and Goodman, 1999). Between 1974 and 1989, NCI had extracted bark from about 7500 trees (Snader, 1990) mostly for investigative research. After 1984, when taxol entered phase I clinical trials, the order increased gradually. Until at least the end of $20^{\text {th }}$ century, this tree was still the main source of the molecule (Walsh and Goodman, 1999), with the yield of only about $0.004 \%$, since approximately $0.5 \mathrm{~g}$ of taxol isolated requires around $12 \mathrm{~kg}$ of air-dried stem and bark (Wall and Wani, 1996). While a full course of treatment for a patient may require $2 \mathrm{~g}$ of taxol, being administrated several times over many months (Strobel et al., 1996). Rendering to those facts, the synthesis of taxol was then developed.

Although it was around the end of the $20^{\text {th }}$ century when the semisynthetic method (conversion of baccatin III or 10-deacetylbaccatin III) obtained from Taxus spp. to taxol) (Stierle et al., 1994; Denis et al., 1988) and total synthesis was introduced (Nicolau et al., 1994), problem remained, since those multistep processes seemed uneconomical. In order to lower the price of taxol, fermentation process was then developed. The discovery of Taxomyces andreanae (organism other than Taxus spp. being able to produce taxol) was the first to be demonstrated (Stierle et al., 1994). Unfortunately, the yields of taxol and taxanes obtained was low. Research on the development of synthesis and biosynthesis technique in obtaining taxol is recently still ongoing to develop more effective routes to this biocompound, together with the investigation of more biologically active and easier to synthesize molecule derived from the molecule (Guo et al., 2006). Furthermore, biotechnological approach was also conducted, in order to establish highly productive cell cultures at the industrial level (Exposito et al., 2009).

The review above shows that the development of anticancer drug which is based on the natural materials led to a serendipitous and exhausting research, spanning over a long period of time. Thus, anticancer drug development paradigm which is based on the exploration of natural materials led to the slow development of cancer drug discovery in Indonesia. However, previous studies on natural products brings along huge amount of information allowing a rapid development of it through translational researches on targeted therapy, which is promising. Besides, 
further exploration may also provide scientific basis and targeted therapy approach for the application of natural products that are still widely used, particularly on cancer treatment, both solely and in combination with established chemotherapeutic agents.

\section{Translational Drug Development}

Translational research is a concept of research with a shortcut that may shorten the path of new drug discovery. With the basis of bioinformatics-genomics and the abundant information on molecular targeting of pathogenesis biomarker, we may computationally design a molecule predicted to be potentially active and easily synthesized. This model may predict a molecule as potent candidate from genotypic level to then brought into phenotypic level (Fig. 3).
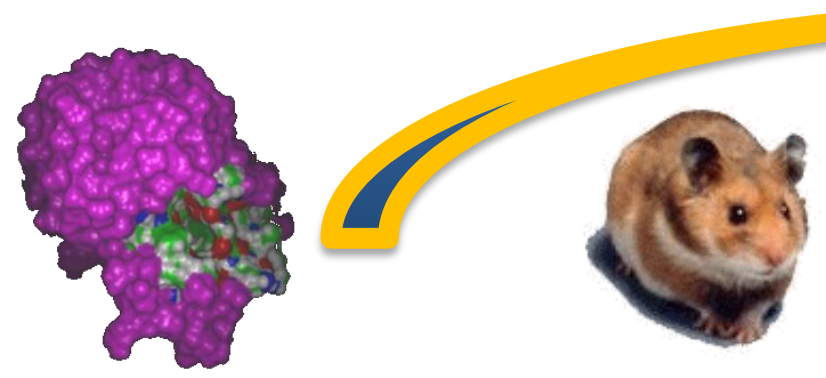

\section{Bioinformatics-Genomic \\ Molecular target-biomarker \\ Clinical-basic research}

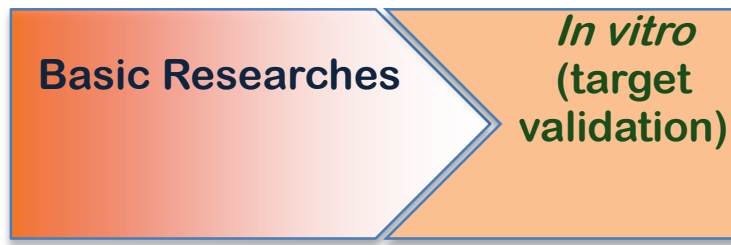

Figure 3. Basic concept of translational research, by analyzing interactions in genotypic level to predict phenomenon in phenotypic level, giving the chance to skip several high-failure-risky steps of drug development.

Identification of the protein markers in a specific cancer is essential for developing chemical library of molecules that are potential to have specific interactions on them. The specific interaction of receptor and its ligands is expected to modulate the normal effect of the protein. This model of interaction ensures more effectiveness of the agent when administrated solely and may decrease the side effect caused by chemotherapeutic agents when applied in combination. This strategy is effectively supported by the increasing techniques in drug discovery based on molecular modeling employing computer modeling based drug design. An interesting example of the drug being discovered based on molecular modeling is the discovery of lapatinib as anti-cancer with specific target on HER-2 and EGFR to overcome the resistance of cancer to Herceptin (Konecny et al., 2008).

HER-2, or HER-2/neu or Erb-B2 receptor, is a member of the EGFR superfamily, a tyrosine kinases transmembrane receptor. This growth factor receptor influences the growth, survival, metastasis, invasiveness, and angiogenesis of tumor cells (Laskin et al., 2004). Since HER-2 is expressed as the hallmark of several cases of malignant breast cancer, such receptor has been a promising target in breast cancer. Thus, HER-2 becomes the important target in the inhibition of cell proliferation. One drug that is popularly used which targets HER-2 receptor is Herceptin.

Herceptin is clinically effective for breast cancer with HER2 over expression, but breast cancer patients develop resistance in prolonged used, caused by elevated level of EGFR expression. Therefore, EGFR is an important target in breast cancer drug development. Gefitinib (Fig. 4) is a small molecule given orally and works by blocking the mechanism of EGFR at the ATP binding site, thereby inhibiting proliferation, differentiation, and angiogenesis (Birnbaun et al., 2005). On the other hand, gefitinib causes resistance and secondary mutation (Yang et al., 2005). To overcome the secondary mutation caused by gefitinib, one has developed WZ4002, a compound that targets EGFR without causing other resistance mechanism. WZ4002 is selective to mutated EGFR with no effect on wild type EGFR 
(Zhou et al., 2009). Therefore, unless some efforts are taken to overcome the phenomenon, there would be no effective treatment to breast cancer remains.<smiles>COc1cc2ncnc(Nc3ccc(F)c(Cl)c3)c2cc1OCCCN1CCOCC1</smiles>

Figure 4. Chemical structure of Gefitinib

EGFR family has four members that their binding with proper ligands lead to the activation of signaling cascades involved in cell proliferation and survival (Nahta et al., 2003; Moy and Gross, 2006). Although ligands for HER-2 are not known, it plays a role in EGFR-family signaling through heterodimerization with other members of the family (Rusnak et al., 2001). Since the overexpression of EFGR and HER-2 are the hallmarks of some cases of breast cancer, agents inhibiting both EGFR and HER2 might be more effective against cancer than those targeting either receptor alone. This idea led to the development of lapatinib (Moy et al., 2007).

Lapatinib (Fig. 5) is a tyrosine kinase inhibitor that works on both EGFR and HER2 tyrosine kinase domains (Fig. 6) (Moy and Goss, 2006; Rusnak et al., 2001; Konecny et al., 2006). Not only showed potent activity against cancers with overexpression of EGFR and HER2, the drug is active against cell lines that are resistant to herceptin, thus promising in patients with trastuzumab-resistant cancers. Besides, since lapatinib is a small molecule that is able to penetrate the blood brain barrier, it may also overcome the problem of herceptin's disability to treat or prevent brain metastases that develop in about one-third of patients with HER2 overexpressing metastatic breast cancer (Moy and Goss, 2006; Clayton et al., 2004).<smiles>CS(=O)(=O)CCNCc1ccc(-c2ccc3ncnc(Nc4ccc(OCc5cccc(F)c5)c(Cl)c4)c3c2)o1</smiles>

(a)

Figure 5. Chemical structure of Lapatinib (a) and its docking with EGFR (Wood et al., 2004) (b)

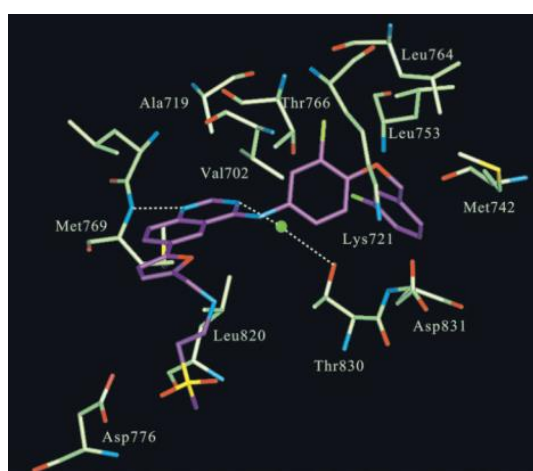

(b)
Structural biology of protein kinase has given detail insights into catalytic domain of kinases to develop selective kinase inhibitor (Cowan-Jacob et al., 2009). Crystal structure of protein explain us binding affinity between kinase inhibitor and receptor. Some computational models have been developed and seem to be useful for ligand scening, ligand docking, and ligand activity profiling studies. Resistance of kinase domain because of mutation contribute to stability of conformation of kinase. By knowing structural biology of kinase, kinase inhibitor may be designed to overcome the resistance problems. According to those facts, we may see the success and ongoing rapid discoveries with the paradigm of translational research. 


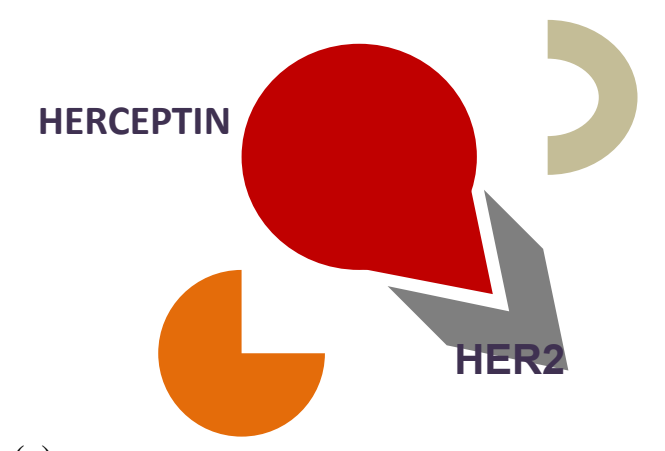

(a)

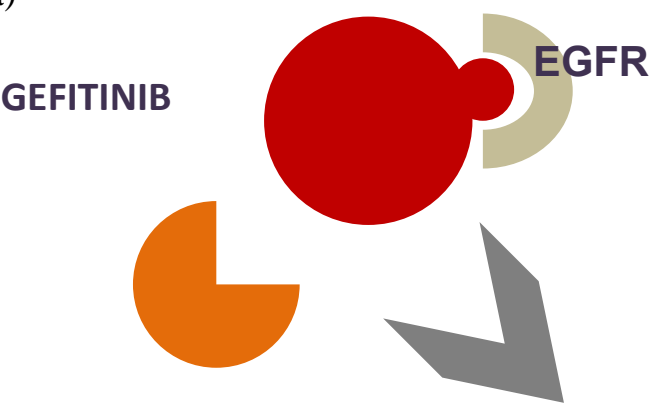

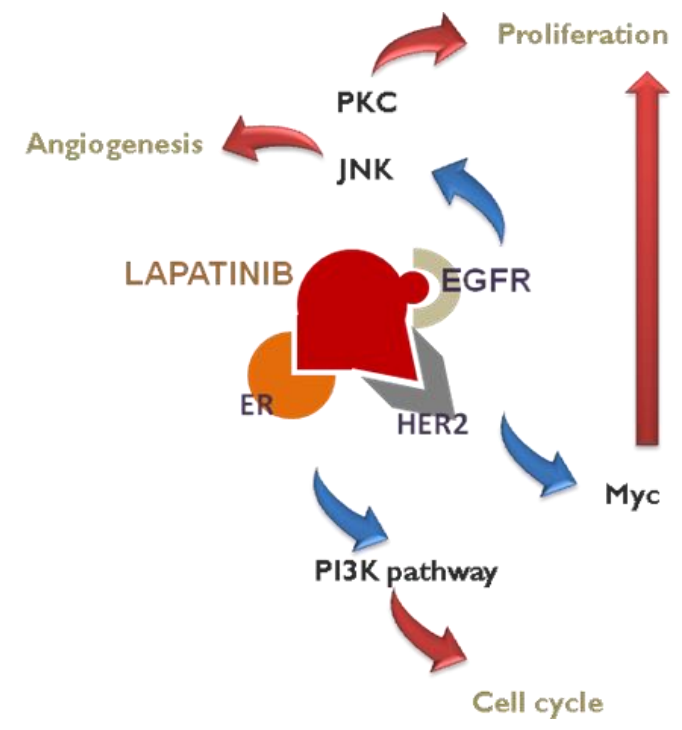

(c)

(b)

Figure 6. Illustrations of interactions between herceptin and its receptor (a), gefitinib and its receptor (b), and lapatinib possessing triple receptor as targets, along with the downstream proteins involved (c)

Tyrosine kinase inhibitor is one promising approach in developing drug for cancer targeted therapy, since kinases do the protein phosphorylation, thus play an important role in regulating signal transductions involved in proliferation, differentiation, migration, and apoptosis of cells. In some types of cancer, mutation or overexpression of certain tyrosine kinases occur (Broekman et al., 2011). Lapatinib is a tyrosine kinase inhibitor that works on both EGFR and HER2, two receptors that are overexpressed in some cases of cancer (Moy and Goss, 2006; Rusnak et al., 2001; Konecny et al., 2006). Studies showed that the growth of tumor cells expressing those receptors are inhibited by lapatinib both in vitro and in vivo (Johnston and Leary, 2006). While leflunomide, a soluble small molecule tyrosine kinase inhibitor, reduced tyrosine phosphorylation of JAK3 and STAT6 in B cells (Siemasko et al., 1998). Besides, leflunomide also could inhibit MAP kinase activity (Rebbaa et al., 1996).

Another tyrosine kinase inhibitor, sutent, inhibited tumor growth, metastasis, angiogenesis, and cell proliferation in a mouse model of mammary cancer (Tanaka et al., 2011). Sutent, which is also known as sunitinib, targets stem-cell factor receptor (KIT or SCFR) and FMS-like tyrosin kinase-3 (FLT3) that are involved in prooncogenic pathway and also VEGFR and PDGFR that are known to play a role in angiogenesis signal transduction (Christensen, 2007; Nishioka et al., 2009).

The steroid hormone estrogen plays an important role in the development and differentiation of breast and endometrial cells, thus may have certain effects in the growth of cancer, either directly by activating oncogenic pathways or indirectly via mitogenic stimulus (Glaeser et al., 2006). However, estrogen also plays an important role in maintaining bone density, cholesterol level, and reproductive tissues (Jordan, 2004). Those effects are mediated by specific receptor that is estrogen receptor (ER). Hence, ER targeting is one approach of both chemoprevention and cancer targeted therapy (Manni et al., 2011). Tamoxifene, a triphenylethylene, is a selective estrogen receptor modulator (SERM) which is able to inhibit estrogen binding to ER and possess both estrogen agonist activity in some tissues and antagonist activity in others (Muchmore, 2000; Osborne, 1998; Sato et al., 1996). Subsequently, G1 phase of cell cycle arrest occurs (Osborne, 1998). It was proven to downregulate endometrial ER (PerezLopez and Comenge, 1993). Tamoxifen also possesses agonist activity in certain tissues, thus categorized as SERM (Muchmore, 2000). Raloxifene possesses estrogen agonist activity in bone and lipids, and antagonist activity in breast and uterus (Khovindhunkit and Shoback, 1999; Muchmore, 2000). This nonsteroidal benzothiphene inhibits human uterine leiomyoma 
cells by increasing $\mathrm{Bcl}-2$ protein expression inducing apoptosis in low concentration and promote their growth in high concentration in vitro (Buelke-Sam et al., 1998; Liu et al., 2006).

Raloxifene that is a ER $\beta$ agonist suppressed proliferation and increased apoptosis of AOMinduced colon tumor (Rao et al., 2006). Both compounds mentioned above are classified as SERMs since both estrogen agonist and antagonist activity have been observed, whilst fulvestrant, a commonly used adjuvant in breast cancer therapy, is an ER pure antagonist without known agonist effect (Jones, 2003; Osborne et al., 2004). Possessing distinctive different chemical structure compared to SERMs, this $7 \alpha$-alkylsulphyl analogue of estrogen binds ER much stronger than tamoxifen does (Wakeling and Bowler, 1987 cit. Osborne et al., 2004; Wakeling et al., 1991 cit. Osborne et al., 2004). Fulvestrant inhibit ER signaling by blocking and accelerating the degradation of ER (Osborne et al., 1994).

Table I. Molecular Targeted Anticancer

\begin{tabular}{|c|c|c|c|}
\hline Compound & Molecular structure & Activity & Ref. \\
\hline \multicolumn{4}{|c|}{ Tyrosine Kinase Inhibitor } \\
\hline Lapatinib & & Inhibits EGFR and HER2 & $\begin{array}{l}\text { Moy and Goss, } 2006 \\
\text { Rusnak et al., } 2001 \\
\text { Konecny et al., } 2006\end{array}$ \\
\hline Leflunomide & & Inhibits MAPK activity & Rebbaa et al., 1996 \\
\hline Sutent & & $\begin{array}{l}\text { Inhibits SCFR, FLT3, } \\
\text { VEGFR, PDGFR }\end{array}$ & $\begin{array}{l}\text { Christensen, } 2007 \\
\text { Nishioka } \text { et al., } 2009\end{array}$ \\
\hline \multicolumn{4}{|c|}{ Anti-estrogen and Selective Estrogen Receptor Modulator } \\
\hline Tamoxifen & & $\begin{array}{l}\text { Estrogen agonist and } \\
\text { antagonist }\end{array}$ & $\begin{array}{l}\text { Muchmore, } 2000 \\
\text { Osborne, } 1998\end{array}$ \\
\hline Raloxifene & Raloxifene & $\begin{array}{l}\text { Estrogen agonist and } \\
\text { antagonist }\end{array}$ & $\begin{array}{l}\text { Khovindhunkit and } \\
\text { Shoback, } 1999 \\
\text { Muchmore, } 2000\end{array}$ \\
\hline Fulvestrant & & Anti-estrogen & Jones, 2003 \\
\hline \multicolumn{4}{|c|}{ Tubulin binding } \\
\hline Paclitaxel & & $\begin{array}{l}\text { Promotes tubulin } \\
\text { polymerization }\end{array}$ & $\begin{array}{l}\text { Saijo et al., 1996; } \\
\text { Kingston, } 2009\end{array}$ \\
\hline
\end{tabular}




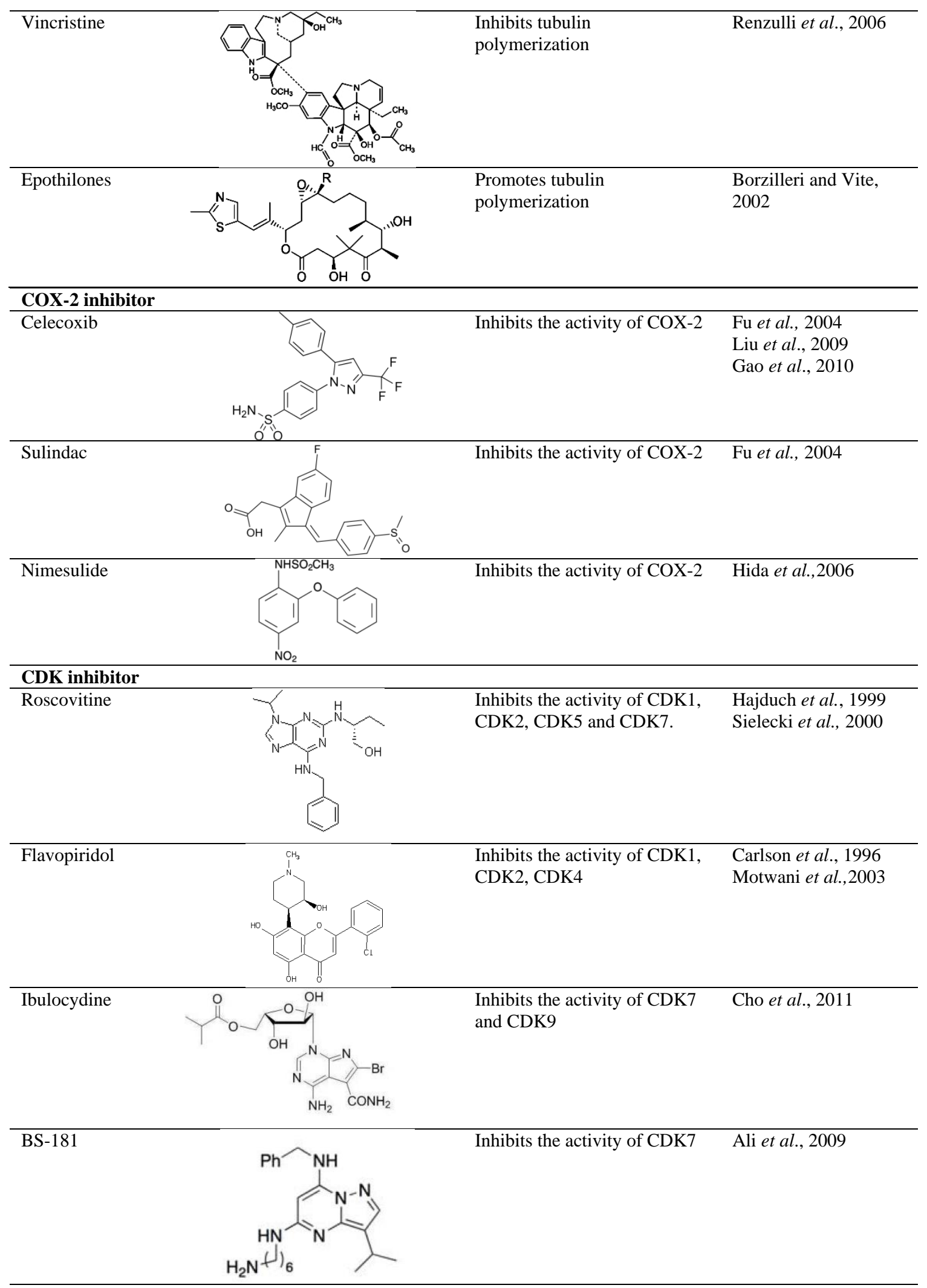




Nelfinavir

There are two anticancer mechanism of actions involving tubulin that are by promoting or by inhibiting tubulin polymerization. Tubulin itself is a protein assemblies and disassemblies in cell replication, thus any interference to it will lead to cell division disruption (mitotic block) and cell death (apoptosis) (Jordan and Wilson, 2004; Kingston, 2009). Paclitaxel, belongs to the taxanes, binds both to an $\mathrm{N}$-terminal unit of $\beta$-tubulin and to the region bounded by AA 217-231 and promotes tubulin polymerization, leading to a stabilization that interferes microtubule dynamic instability (Bhalla, 2003; Rao et al., 1994 cit. Kingston, 2009; Rao et al., 1995 cit. Kingston, 2009; Saijo et al., 1996). Paclitaxel is the very first taxanes being approved for clinical use in cancer treatment. Besides, this molecule also binds to $\mathrm{Bcl}-2$ protein, thus inducing apoptosis (Sinha et al., 2011). Whilst vincristine, belonging to the group of vinca alkaloids, exhibits antimitotic activity by inhibiting microtubule assembly (Renzulli et al., 2006).

Epothilones, molecules built of epoxide, thiazole, and ketone groups, act as anticancer agents with the same mechanism of action as paclitaxel (Borzilleri and Vite, 2002). Epothilones was observed to inhibit growth of cells and to be able to overcome resistance due to P-gp overexpression and specific $\beta$-tubulin mutations (Chou et al., 2001 cit. Borzilleri and Vite, 2002; Su et al., 1997 cit. Borzilleri and Vite, 2002). Not only possessing great antiproliferative activity in vitro, this group of molecules induces cell death in paclitaxel-resistant tumor cells in much lower concentration compared to paclitaxel (Carlomagno et al., 2003).

Cyclooxygenase-2 (COX-2) is important enzyme in imflammation and carcinogenesis. Expression of COX-2 stimulates the occurrence of cancer by increasing prostanoid production that increases cancer cell proliferation (Kinoshita et al., 1999). Upregulation of COX-2 causes upregulation of Bcl-2 that leads to apoptosis resistancy (Sheng et al., 1998) and causes excessive accumulation of prostaglandins (PGH2) which catalyzes the conversion of procarcinogen to be carcinogen (Palozza et al., 2004). Inhibition of COX-2 may help treat and prevent cancer.

COX-2 inhibitors are currently being studied in some cancers such as breast cancer and colon cancer treatment. Anticancer activity of celecoxib on gastric cancer cells is mediated by cell-cycle arrest and apoptosis, and not by COX-2 or PGE2 suppression alone (Cho et al.,2007). Anticancer activity of celecoxib is COX-2independent in HT-29 and PC-3 cells (Gao et al., 2010). Celecoxib inhibits gastric carcinoma cells via cyclooxygenase-2-dependent pathway by decreasing $\mathrm{Bcl}-2$, and cyclooxygenase-2independent pathway by increasing p21 and p27 (Liu et al., 2009). Celecoxib and sulindac induce apoptosis, suppress proliferation and reduce angiogenesis and weaken invasiveness of gastric cancer cells (Fu et al., 2004). The other COX-2 inhibitor anticancer drug is nimesulide. COX-2 expression in NSCLC cells may affect their responsiveness to COX-2 inhibitors, so the apoptosis induction of nimesulide on non-small cell lung cancer cell is correlated to inhibition of COX-2 expression (Hida et al., 2006).

Cell cycle is regulated by cyclin-dependent kinases (CDK), which are activated during the cell moves from $\mathrm{G} 1$ to $\mathrm{S}$ phase into $\mathrm{G} 2$ and $\mathrm{M}$ phases, which form a complex with cyclin. CDK activity is controlled by cell cycle inhibitor proteins known as CDK inhibitors (CKI). Development of CDK inhibitors as anticancer agents has been interesting topic. Roscovitine is a potent but reversible inhibitor of CDK1, CDk2, CDK5 and CDK7 by acting as a competitor of ATP binding (Hajduch et al., 1999; Sielecki et al.,2000). Flavopiridol has been shown to induce cell cycle arrest and apoptosis in various tumor cells in vitro and in vivo. Flavopiridol induces cell cycle arrest in G1 phase by inhibition of CDK4 and/or CDK2 kinase activity (Carlson et al., 1996). Flavopiridol inhibits activity of cyclin B1/CDK1 kinase on MKN-74 human gastric cells (Motwani et al., 2003). Ibulocydine (an isobutyrate prodrug of the specific Cdk inhibitor, BMK-Y101), a candidate anticancer drug for HCC, inhibits HCC cells proliferation and induces apoptosis by inhibiting CDK7 and CDK9 (Cho et al., 2011). BS-181 is a synthetic compound developed based on computational drug development. BS-181 shows strong CDK inhibition activity especially CDK7, induces cell cycle arrest and apoptosis of cancer cells, and shows in vivo antitumor activity (Ali et al., 2009).

Protease inhibitors perturb replication of HIV (human immunodeficiency virus) and 
interfere with the protease enzyme. Blocking of protease leads to abberation of the new copies of HIV formation. Nelfinavir is one HIV protease inhibitor that is developed as anticancer. Development of nelfinavir as anticancer is directed by toxic effect of nelfinavir associated to inhibition of Akt. Nelfinavir induces cell death by caspase dependent and independent pahtway, decreases the viability of drug-resistant breast cancer cell lines and inhibits NSCLC xenografts growth that is associated with induction of ER stress, autophagy, and apoptosis (Gills et al., 2007).

The abundance of information on the activity and molecular targets of phytochemicals particularly in the treatment of cancer, supported by studies on receptors being involved in carcinogenesis allows a promising translational research with the basis of cancer targeted therapy. Computational study resulting prediction of new active molecules may bring along an effective and efficient discovery and development of new drugs possessing anticancer activity. Besides, further and comprehensive studies on targeted therapy let us conduct a molecular approach in finding the scientific basis of natural products application (as traditional medicine). The focus of drug development in Indonesia should be immediately turned, from the development of herbal products to the development of modern medicine.

\section{REFERENCES}

Ali, S., Heathcote, D.A., Kroll, S.H.B., Jogalekar, A.S., Scheiper, B., Patel, H., Brackow, J., Siwicka, A., Futcher, M.j., Periyasamy, M., Tolhurst, R.S., Kanneganti, S.K., Snyder, J.P., Liotta, D.C., Aboagye, E.O., Barret, A.G.M. and Coombes, R.C., 2009, The Development of a Selective CyclinDependent Kinase Inhibitor That Shows Antitumor Activity, Cancer Res., 69(15), 6208-6215.

Bhalla, K.N., 2003, Microtubule-targeted Anticancer Agents and Apoptosis, Oncogene, 22, 9075-9086.

Borzilleri, R.M. and Vite, G.D., 2002, Epothilones: New Tubulin Polymerization Agents in Preclinical and Clinical Development, Drugs for the Future, 27(I2), II49-I I63.

Bouker, K.B., Skaar, T.C., Riggins, R.B., Harburger, D.S., Fernandez, D.R., Zwart, A., Wang, A. and Clarke, R., 2005, Interferon regulatory factor-I (IRF-I) Exhibits Tumor Suppressor Activities in Breast Cancer Associated with Caspase Activation and Induction of Apoptosis, Carcinogenesis, 26(9), 15271535.
Broekman, F., Giovvannetti, E. and Peters, G.J., 20II, Tyrosine Kinase Inhibitors: Multitargeted or Single-targeted?, World J. Clin. Oncol., 2(2), 80-93.

Buelke-Sam, J., Bryant, H.U. and Francis, P.C., 1998, The Selective Estrogen Receptor Modulator, Raloxifene: An Overview of Nonclinical Pharmacology and Reproductive and Developmental Testing, Reprod. Toxicol., I 2(3), 2|7-22I.

Carlomagno, T., Blommers, M.J.J., Meiler, J., Jahnke, W., Schupp, T., Petersen, F., Schinzer, D., Altmann, K.H., and Griesinger, C., 2003, The High-Resolution Solution Structure of Epothilone A Bound to Tubulin: An Understanding of the Structure-Activity Relationships for A Powerful Class of Antitumor Agents, Angew. Chem. Int. Ed., 42, 25।I-25।5.

Carlson, B.A., Dubay, M.M., Sausville, E.A., Brizuela, L., and Worland, P.J., 1996, Flavopiridol Induces $G_{1}$ Arrest with Inhibition of Cyclin-dependent Kinase (CDK) 2 and CDK4 in Human Breast Carcinoma Cells, Cancer Res., 56, 2973.

Cho, S.J., Kim, N., Kim, J.S., Jung, H.C., and Song, I.S., 2007, The Anti-Cancer Effect of COX-2 Inhibitors on Gastric Cancer Cells, Dig Dis Sci, 52, I7|3-172|

Cho, S.J., Kim, Y.J., Surh, Y.J., Kim, B.M., and Lee, S.K., 20II, Ibulocydine, A Novel Prodrug CDK Inhibitor, Effectively Induces Apoptosis In Hepatocellular Carcinoma Cells, The Journal of Biological Chemistry.

Chou, T.C., O'Connor, O.A., Tong, W.P., Guan, Y., Zhang, Z.G., Stachel, S.J., Lee, C, and Danishefsky, S.J., 200I, The Synthesis, Discovery, and Development of A Highly Promising Class of Microtubule Stabilization Agents: Curative Effects of Desoxyepothilones $B$ and $F$ against Human Tumor Xenografts in Nude Mice, Proc. Natl. Acad. Sci. USA, 98, 8II3-8II8 in Borzilleri, R.M. and Vite, G.D., 2002, Epothilones: New Tubulin Polymerization Agents in Preclinical and Clinical Development, Drugs for the Future, 27(I2), II49-I I63.

Christensen, J.G., 2007, A Preclinical Review of Sunitinib, A Multitargeted Receptor Tyrosine Kinase Inhibitor with Antiangiogenic and Antitumor Activities, Ann. Oncol., 18(10), x3-x/0.

Clayton, A.J., Danson, S., Jolly, S., Ryder, W.D.J., Burt, P.A., Stewart, A.L., Wilkinson, P.M., Welch, R.S., Magee, B., Wilson, G., Howell, A., and Wardley, A.M., 2004, Incidence of 
cerebral metastases in patients treated with trastuzumab for metastatic breast cancer, Br. J. Cancer, 91, 639-643.

Cowan-Jacob, S.W., Mobitz, H. and Fabbro, D., 2009, Structural biology Contributions to Tyrosine Kinase Drug Discovery, Current Opinion in Cell Biology, 2 I , 280-287.

Cragg, G.M. and Newman, D.J., 2005, Plants as a source of anti-cancer agents, J. Ethnopharmacol., I 00, 72-79.

Denis, J.N., Greene, A.E., Guenard, D., and Potier, P., Highly Efficient, Practical Approach to Natural Taxol, J. Am. Chem. Soc., 220, 5917.

Exposito, O., Bonfill, M., Moyano, E., Onrubia, M., Mirjalili, M.H., Cusido, R.M., and Palazon, J., 2009, Biotechnological Production of Taxol and Related Taxoids: Current State and Prospects, Anti-Cancer Agents in Medicinal Chemistry, 9, 109-121.

Fu, S.L., Wu, Y.L., Zhang, Y.P., Qiao, M.M., and Chen, Y., 2004, Anti-cancer effects of COX-2 Inhibitors and Their Correlation with Angiogenesis and Invasion in Gastric Cancer, World J Gastroenterol, I O(13), I97I1974.

Gao, P., Guan, L. and Zheng, J., 2010, Role of Leukotriene B4 in Celecoxib-Mediated Anticancer Effect, Biochem Biophys Res Commun., 402(2), 308-3II.

Gills, J.J., LoPicollo, J., Tsurutani, J., Shoemaker, R.H., Best, C.J.M. and Abu-Asab, M.S., 2007, Nelfinavir, A Lead HIV Protease Inhibitor, Is a Broad-Spectrum, Anticancer Agent that Induces Endoplasmic Reticulum Stress, Autophagy, and Apoptosis In vitro and Invivo, Clin Cancer Res., I3, 5183-5194.

Glaeser, M., Niederacher, D., Djahansouzi, S., Hanstein, B., Dittrich, R., Beckmann, M.W., Fasching, P.A. and Ackermann, S., 2006, Effects of the Antiestrogens Tamoxifen and Raloxifene on the Estrogen Receptor Transactivation Machinery, Anticancer Res., 26, 725-744.

Guo, B.H., Kail, G.Y., Jin, H.B. and Tang, K.X., 2006, Taxol Synthesis, Afr. J. Biotech., 100 (I), 57-70

Hajduch, M., Havlieek. L., Vesely, J., Novotny, R., Mihal, V. and Strnad, M., 1999, Synthetic Cyclin Dependent Kinase Inhibitors, New Generation of Potent Anticancer Drugs, Adv Exp Med Biol, 457, 34l-353.

Hanahan, D. and Weinberg, R.A., 20II, The Hallmark of Cancer: The Next Generation, Cell, I 00, 57-70.

Hida, T., Kozaki, K., Muramatsu, H., Masuda, A., Shimizu, S., Mitsudomi, T., Sugiura, T.,

\section{[iscc. IIJ]ClC}

Ogawa, M. and Takahashi, T., 2006, Cyclooxygenase-2 Inhibitor Induces Apoptosis and Enhances Cytotoxicity of Various Anticancer Agents in Non-Small Cell Lung Cancer Cell Lines, Clinical Cancer Research, 6, 2006-20II.

Horwitz, S.B., 2004, Personal Recollections on the Early Development of Taxol, J. Nat. Prod., 67, $136-138$.

Imai, Y., Ishikawa, E., Asada, S., and Sugimoto, Y., 2005, Estrogen-Mediated Post Transcriptional Down-regulation of Breast Cancer Resistance Protein/ABCG2, Cancer Res, 65, 596-604.

Johnston, S.R. and Leary, A., 2006, Lapatinib: A Novel EGFR/HER2 Tyrosine Kinase Inhibitor for Cancer, Drugs Today (Barc.), 42(7), 44I-453.

Jones, S.E., 2003, Fulvestrant: An Estrogen Receptor Antagonist that Downregulates the Estrogen Receptor, Semin. Oncol., 30(5 suppl. 16), 14-20.

Jordan, M.A. and Wilson, L., 2004, Microtubules as A Target for Anticancer Drugs, Nat. Rev., Cancer, 4, 253-265

Jordan, V.C., 2004, Selective Estrogen Receptor Modulation: Concept and Consequences in Cancer, Cancer cell, 5(3), 207-2I 3.

Khovidhunkit, W., and Shoback, D.M., 1999, Clinical Effects of Raloxifene Hydrochloride in Women, Clin. Rev., I30(5), 43 I-439.

Kingston, D.G.I., 2009, Tubulin-Interactive Natural Products as Anticancer Agents (I), J. Nat. Prod., 72(3), 507-5I 5.

Kohler, J., and Goldspiel, B.R., 1994, Evaluation of new drug Paclitaxel (Taxol), Pharmacotherapy, I4, 3-34.

Kolata, G., 1991, Tree Yields a Cancer Treatment, but Ecological Cost may be High, New York Times, I, I 3 May.

Konecny, G.E., Pegram, M.D., Venkatesan, N., Finn, R., Yang, G., Rahmeh, M., Untch, M., Rusnak, D.W., Spehar, G., Mullin, R.J., Keith, B.R., Gilmer, T.M., Berger, M., Podratz, K.C., and Slamon, D.J., 2006, Activity of the dual kinase inhibitor lapatinib (GW572016) against HER-2-overexpressing and trastuzumab-treated breast cancer cells, Cancer Res., 66, 1630-1639.

Konecny, G.E., Venkatesan, N., Yang, G., Dering, J., Ginther, C., Finn, R., Rahmeh, M., Fejzo, M.S., Toft, D., Jiang, S.W., Slamon, D.J. and Podratz, K.C., 2008, Activity of Lapatinib a Novel HER2 and EGFR Dual Kinase Inhibitor in Human Endometrial Cancer Cells, Br. J. Cancer, 98, 1076-1084. 
Kumar, R., Vadlamudi, R.K., and Adam, L., 2000, Apoptosis in Mammary Gland and Cancer, Endocr. Relat. Cancer, 7, 257-269.

Laskin, J.J. and Sandler, A.B., 2004, Epidermal Growth Factor Receptor: a Promising Target in Solid Tumours, Cancer Treat Rev, $30,1-17$.

Lee, K.W., Bode, A.M. and Dong,Z., 20II, Molecular Targets of Phytochemicals for Cancer Prevention, Nature Reviews Cancer, I I, 2| |-2|8.

Liu, H., Huang, P., Xu, X., Liu, J. and Guo, C., 2009, Anticancer Effect of Celecoxib via COX-2 Dependent and Independent Mechanisms in Human Gastric Cancers Cells, Dig. Dis. Sci., 54, I4I8-I424.

Liu, J., Matsuo, H., Xu, Q., Chen, W., Wang, J. and Maruo, T., 2007, Concentration-dependent Effects of A Selective Estrogen Receptor Modulator Raloxifene on Proliferation and Apoptosis in Human Uterine Leiomyoma Cells Cultured In vitro, Hum. Reprod., 22(5), 1253-1259.

Manni, A., Xu, H., Washington, S., Aliaga, C., Das, A., Cooper, T., Richie, J.P. Jr., Prokopczyk, B., Calcagnotto, A., Trushin, N., Van den Heuvel, J.P., Hamilton, C., Demers, L.M., Liao, J., Verderame, M.F. and El-Bayoumy, K., 20II, The Effects of Tamoxifen and Fish Oil on Mammary Carcinogenesis in Polyoma Middle T Transgenic Mice, Horm Cancer, DOI 10.1007/s I 2672-0I I-0078-2.

Motwani, M., Rizzo, C., Sirotnak, F., She, Y. and Schwart, G.K., 2003, Flavopiridol Enhances the Effect of Docetaxel in Vitro and in Vivo in Human Gastric Cancer Cells, Mol Cancer Ther., 2, 549-555.

Moy, B. and Goss, P.E., 2006, Lapatinib: Current Status and Future Directions in Breast Cancer, Oncologist, I I, I047-1057.

Moy, B., Kirkpatrick, P., Kar, S. and Goss, P., 2007, Lapatinib, Nature reviews drug discovery, 6, $431-432$.

Muchmore, D.B., 2000, Raloxifene: A Selective Estrogen Receptor Modulator (SERM) with Multiple Target System Effects, The Oncologist, 5(5), 388-392.

Nahta, R., Hortobagya, G.N. and Estevaa, F.J., 2003, Growth factor receptors in breast cancer: potential for therapeutic intervention, Oncologist, 8, 5- 17.

Nicolau, K.C., Yang, Z., Liu, J.J., Ueno, H., Natermet, P.G., Guy, R.K., Claiborne, C.F., Renaud, J., Couladouros, E.A., Paulvannann, K. and Sorensen, E.J., 1994, Total Synthesis of Taxol, Nature, 367, 630-634.
Nishioka, C., Ikezoe, T., Yang, J. and Yokoyama, A., 2009, Sunitinib, An Orally Available Receptor Tyrosine Kinase Inhibitor, Induces Monocytic Differentiation of Acute Myelogenous Leukemia Cells that is Enhanced by I,25-dihydroxyvitamin $D_{3}$, Leukemia, 23, 2 I7l-2I73.

Osborne, C.K., 1998, Tamoxifen in the Treatment of Breast Cancer, N. Engl. J. Med., 339, I609-1618.

Osborne, C.K., Jarman, M., McCague R., Coronado, E.B., Hilsenbeck, S.G., and Wakeling, A.E., 1994, The Importance of Tamoxifen Metabolism in Tamoxifenstimulated Breast Tumor Growth, Cancer Chemother. Pharmacol., 34, 89-95.

Osborne, C.K., Wakeling, A. and Nicholson, R.I., 2004, Fulvestrant: An Oestrogen Receptor Antagonist with A Novel Mechanism of Action, British J Cancer, 90, S2-S6.

Perez-Lopez, F.R., and Comenge, C.B., 1993, Effects of TAmoxifen on Endometrial Estrogen and Progesterone Receptor Concentrations in Women with Fibrocystic Disease of the Breast, Gynecological Endocrinology, 7(3), 185-189.

Rao, C.V., Janakiram, N.B., Swamy, M.V., Guruswamy, S., Patlolla, J.M.R., Thungathurthi, R., Kopelovich, L. and Steele, V.E., 2006, Chemoprevention of Colon Cancer by Raloxifene, A Selective Estrogen Receptor Modulator (SERM), Proc. Amer. Assoc. Cancer Res., 47.

Rao, S., Krauss, N.E., Heerding, J.M., Swindell, C.S., Ringel, I., Orr, G.A. and Horwitz, S.B., 1994, J. Biol. Chem., 269, 3132-3134 in Kingston, D.G.I., 2009, Tubulin-Interactive Natural Products as Anticancer Agents (1), J. Nat. Prod., 72(3), 507-5I5.

Rao, S., Orr, G.A., Chaudary, A.G., Kingston, D.G.I. and Horwitz, S.B., 1995, J. Biol. Chem., 270, 20235-20238 in Kingston, D.G.I., 2009, Tubulin-Interactive Natural Products as Anticancer Agents (I), J. Nat. Prod., 72(3), 507-5I5.

Rebba, A., Hurh, J., Yamamoto, H., Kersey, D.S. and Bremer, E.G., 1996, Ganglioside GM3 Inhibition of EGF Receptor Mediated Signal Transduction, Glycobiology, 6(4), 399-406.

Renzulli, M.L., Rocheblave, L., Avramova, S.I., Galletti, E., Castagnolo, D., Maccari, L., Forli, S., Manetti, F., Corelli, F. and Botta, M., 2006, A Pharmacophore Modeling Approach to Design New Taxol ${ }^{\circledR}$ Mimics: towards the Synthesis of Potential 
Anticancer and MDR-reversing Agent, ARKIVOC, 8, III-I 30.

Rusnak, D.W., Lackey, K., Affleck, K., Wood, E.R., Alligood, K.J., Rhodes, N., Keith, B.R., Murray, D.M., Knight, W.B., Mullin, R.J. and Gilmer, T.M., 200I, The effects of the novel, reversible epidermal growth factor receptor/ErbB-2 tyrosine kinase inhibitor, GW2016, on the growth of human normal and tumor-derived cell lines in vitro and in vivo, Mol. Cancer Ther., I, 85-94.

Saijo, N., Nishio, K., Obta, S., Arioka, H., Funayama, Y., Fukuoka, K., Kurokawa, H., Nomoto, T., Ishida, T., Yamamoto, N., Tamura, T., Shinkai, T., Eguchi, K., Ohe, Y., Kunito, H., Ohtsu, T. and Sasaki, Y., 1996, Progress in Preclinical and Clinical Studies for the Development of New Anticancer Drugs in Japan, with Emphasis on Taxanes, Cancer Chemother. Pharmacol., 38, SII-SI5.

Sato, M., Rippy, M.K., and Bryant, H.U., 1996, Raloxifene, Tamoxifen, Nafoxidine, or Estrogen Effects on Reproductive and Nonreproductive Tissues in Ovariectomized Rats, FASEB J., 10, 905912.

Sheng, H., Shao, J., Morrow, J.D., Beauchamp, D., and Dubois, R.N., 1998, Modulation of Apoptosis and $\mathrm{Bcl}-2$ Expression by Prostaglandin E 2 in Human Colon Cancer Cells, Cancer Res, 58, 362-366.

Sielecki, T.M., Boylan, J.F., Benfield, P.A., and Trainor, G.L., 2000, Cyclin-dependent Kinase Inhibitors: Useful Targets In Cell Cycle Regulation, J. Med. Chem., 43, I-I8.

Siemasko, K., Chong, A.S.F., Jack, H.M., Gong, H., Williams, J.W., and Finnegan, A., 1998, Inhibition of JAK3 and STAT6 Tyrosine Phosphorylation by the Immunosuppresive Drug Leflunomide Leads to A Block in IgGI Production, J. Immunol., 160, I58I-I588.

Sinha, R., Vidyarthi, A.S., and Shankaracharya, 201I, A Molecular Docking Study of Anticancer Drug Paclitaxel and Its Analogues, Indian J. Biochem. and Biophysics, 48, $10 \mathrm{I}-105$.

Snader, K., 1990, Speaker abstract (n.t.). in: workshop of Taxol and Taxus: Current and Future Perspectives, National Cancer Institute, Bethesda.

Stierle, A., Stierle, D., Strobel, G., Bignami, G., and Grothaus, P., 1994, Bioactive Metabolites of the Endophytic Fungi of Pacific Yew, Taxus brevifolia, in George, G.I., Chen, T.T., Ojima, I., and Vyas, D.M., Taxane Anticancer Agents (Basic Science Current Status), American
Chemical Society Symposium Series no. 583, American Chemical Society, Washington D.C., 8I-97.

Strobel, G., Yang, X., Sears, J., Kramer, R., Sidhu, R.S., and Hess, W.M., 1996, Taxol from Pestalotiopsis microspora, an Endophytic Fungus of Taxus wallachiana, Microbiology, I 42, 435-440.

Su, D.S., Balog, A., Meng, D., Bertinato, P., Danishefsky, S.J., Zheng, Y.H., Chou, T.C., He, L., and Horwitz, S.B., 1997, StructureActivity Relationships of the Epothilones and the First In vivo Comparison with Paclitaxel, Angew. Chem. Int. Ed. Engl., 36, 2093-2096 in Borzilleri, R.M. and Vite, G.D., 2002, Epothilones: New Tubulin Polymerization Agents in Preclinical and Clinical Development, Drugs for the Future, 27(I2), II49-I I 63.

Suffness, M., 1994, Is Taxol a Surrogate for A Universal Regulator of Mitosis?, In vivo, 8, 867-878.

Tanaka, Y., Shibata, M.A., Morimoto, J., and Otsuki, Y., 20II, Sunitinib Suppresses Tumor Growth and Metastases in A Highly Metastatic Mouse Mammary Cancer Model, Anticancer Res., 3 I (4), I 225-I 234.

Wakeling, A.E. and Bowler, J., 1987, Steroidal Pure Antioestrogens, J. Endocrinol., I I 2, R7-R I0 in Osborne, C.K., Wakeling, A., and Nicholson, R.I., 2004, Fulvestrant: An Oestrogen Receptor Antagonist with A Novel Mechanism of Action, British J Cancer, 90, S2-S6.

Wakeling, A.E., Dukes, M., and Bowler, J., I99I, A Potent Spesific Pure Antiestrogen with Clinical Potential, Cancer Res., 5 I, 38673873 in Osborne, C.K., Wakeling, A., and Nicholson, R.l., 2004, Fulvestrant: An Oestrogen Receptor Antagonist with A Novel Mechanism of Action, British J Cancer, 90, S2-S6.

Wall, M.E., and Wani, M.C., 1996, Campothecin and Taxol: from Discovery to Clinic, J. Ethnopharmacol., 5 I, 239-254.

Walsh, V., and Goodman, J., 1999, Cancer Chemotherapy, Biodiversity, Public and Private Property: The Case of the Anticancer Drug Taxol, Social Science and Medicine, 49, $1215-1225$.

Wani, M.C., Taylor, H.L., Wall, M.E., Coggon, P., and McPhail, A.T., 197I, Plant Antitumor Agents, VI: the Isolation and Structure of Taxol, a Novel Antileukemic and Antitumor Agent from Taxus brevifolia, $J$. of the American Chemical Society, 93, 2325-2327. 


\section{[iscc. IIJ]ClC}

Yang, C.H., Huang, C.J., Yang, C.S., Chu, Y.C., Cheng, A.L., Whang-Peng, J., Yang, P.C., 2005, Gefitinib Reverses Chemotherapy Resistance in Gefitinib-Insensitive Multidrug Resistant Cancer Cells Expressing ATPbinding Cassette Family Protein, Cancer Res., 65(I5), 6943-6949.

Zhou, W., Ercan, D., Chen, L., Yun, C.H., Li, D., Capelleti, M., Cortot, A.B., Chirleac, L., lacob, R.E., Padera, R., Engen, J.R., Wong, K.K., Eck, M.J., Gray, N.S., and Janne, P.A., 2009, Novel Mutant-Selective EGFR Kinase Inhibitors against EGFR T790M, Nature, 24 (462), I070-1074. 